\title{
ONF Trainee Awards Contribute to Capacity Building in Neurotrauma
}

\author{
Jane Turner, Dan Turner, Richard J. Riopelle, Kent Bassett-Spiers, \\ Corinne Kagan
}

\begin{abstract}
Objective: Injury to the brain and spinal cord is one of the most catastrophic and costly occurrences in the Ontario health system. The objective of the present study was to evaluate the impact of past Ontario Neurotrauma Foundation (ONF) studentships and fellowships in terms of capacity building in the neurotrauma field in Ontario. Method: An online, cross sectional survey amongst past recipients of studentships and fellowships that terminated prior to July 2005. Explicit data were collected on various aspects of career development including current activity, awards and publications. Results: Thirty-six out of 42 (86\%) eligible past trainees responded; $12(33 \%)$ were Masters students, $12(33 \%)$ were $\mathrm{PhD}$ students and 12 (33\%) were Post-Doctoral students. A majority of the recipients $(61 \%)$ are currently involved in neurotrauma-related activities (clinical, research and teaching) in more than $20 \%$ of their time, with no substantial differences between the degree groups. Half the recipients are currently involved in neurotrauma-related research in more than $20 \%$ of their time. The awardees published 1.5 peer-review manuscripts/person-year and received multiple awards. A high majority of our recipients $(86 \%)$ feel that the ONF award had a substantial impact on their career. Conclusions: A high proportion of past award recipients remain involved in neurotrauma activities, especially in research. These results may lead to a cautious conclusion of the positive impact of the ONF studentships and fellowships on neurotrauma capacity building. These results should be considered in strategic planning of funding agencies similar to ONF.
\end{abstract}

RÉSUMÉ: Les bourses de perfectionnement de l'ONF contribuent à bâtir les compétences en neurotraumatologie. Objectif : Les lésions traumatiques du cerveau et de la moelle épinière sont parmi les pathologies les plus catastrophiques et les plus coûteuses dans le système de santé ontarien. L'objectif de cette étude était d'évaluer l'impact des bourses de perfectionnement de l'Ontario Neurotrauma Foundation (ONF) sur l'accroissement des compétences en neurotraumatologie en Ontario. Méthode : Nous avons procédé à une enquête transversale en ligne ciblant les récipiendaires de bourses de perfectionnement qui ont terminé leur stage avant juillet 2005. Des données explicites sur différents aspects de leur cheminement de carrière, particulièrement en ce qui concerne les activités actuelles, les bourses et subventions et les publications ont été recueillies. Résultats : Trente-six des 42 stagiaires éligibles (86\%) ont répondu au sondage. Parmi eux, 12 (33\%) étaient des étudiants à la maîtrise, 12 (33\%) étaient des étudiants au doctorat et 12 (33)\% étaient des étudiants post-doctoraux. La majorité des récipiendaires (61\%) consacrent actuellement plus de $20 \%$ de leur temps de travail à des activités reliées à la neurotraumatologie (clinique, recherche et enseignement), sans différence substantielle entre les différents niveaux de formation. La moitié des récipiendaires consacrent actuellement plus de $20 \%$ de leur temps à la recherche en neurotraumatologie. Ils ont publié en moyenne 1,5 article évalué par des pairs par personne-année et ils ont reçu plusieurs subventions. La grande majorité des récipiendaires de nos bourses (86\%) considèrent que la bourse qu'ils ont reçu de l'ONF a eu un impact important sur leur carrière. Conclusions : Une grande proportion des boursiers demeurent impliqués dans des activités reliées à la neurotraumatologie, surtout en recherche. Ces résultats nous portent à conclure que les bourses de l'ONF, tant au niveau du premier cycle universitaire que des deuxième ou troisième cycles, ont un impact positif sur l'accroissement des compétences en neurotraumatologie. On devrait tenir compte de ces résultats dans la planification stratégique d'organismes de financement comme l'ONF.

Can. J. Neurol. Sci. 2008; 35: 85-90

The field of neurotrauma encompasses spinal cord injury (SCI) and traumatic brain injury (TBI). A research project, commissioned by the Ontario Neurotrauma Foundation (ONF), found that the incidence of SCI and TBI is 3.4 and 55.1/100,000 population per year, respectively (unpublished data of the ONF). Injury to the brain and spinal cord is one of the most catastrophic and costly occurrences in the Ontario health system. A recent report funded by ONF to examine the cost of neurotrauma in Ontario identified that the direct cost alone of spinal cord injury and traumatic brain injury to the provincial health care system exceeds \$466-million annually (unpublished data of the ONF). This cost does not reflect the significant financial and quality of life impact to the injured person, nor the service and societal costs associated with the long-term effects of SCI and TBI.

From the Ontario Neurotrauma Foundation (JT, KBS, CK); The Hospital for Sick Children (DT), University of Toronto, Toronto, Ontario; Department of Neurology and Neurosurgery (RJR), McGill University, Montreal, QC, Canada.

Received May 22, 2007. Final Revisions Submitted October 22, 2007. Reprint requests to: Jane Turner, Ontario Neurotrauma Foundation, 90 Eglinton Avenue East, Suite 404, Toronto, Ontario, M4P 2Y3, Canada. 
According to the World Health Organization, neurotrauma is becoming one of the major causes of death and disability, expected to surpass many other causes in 10-15 years. ${ }^{1}$

The ONF, funded by the Ministry of Health and Long-Term Care, is a health research funding agency devoted to strategic and applied research in the field of neurotrauma in Ontario. The vision of ONF is centred on reducing the impact, incidence and prevalence of neurotraumatic injuries and improving neurotrauma-related quality of life. A solid research capacity is thus essential, and is achieved by creating a cadre of people involved in research, clinical and educational activities related to neurotrauma. Areas which have been identified as having poor research capacity, such as neurotrauma, have been identified by policy makers as a high priority for capacity building. ${ }^{2}$ Fellowship awards, training schemes and bursaries, and the development of support infrastructures are all part of capacity building initiatives. ${ }^{3}$ The Canadian Institute of Aging, for example, supports research capacity building in the field of aging by funding annual awards for trainees, new investigators, and mid-career researchers. ${ }^{4}$ Ontario Neurotrauma Foundation capacity building initiatives have included studentships (Masters and $\mathrm{PhD}$ ) and Post-Doctoral fellowships. Since its establishment in 1998, the ONF has supported 65 studentships and fellowships in a highly competitive application process, of a total sum of $\$ 3.3$ million CAD. Despite the substantial amount of allocated funds, the impact of the studentship and fellowship programs on the capacity building is unknown. To our knowledge, no study has been previously published in the peer-review literature exploring the impact of fellowship and studentship funding on capacity building in the field of neurotrauma.

We, thus, aimed to investigate, by a cross-sectional survey, whether the past capacity building initiatives have succeeded in creating a cadre of people involved in research, clinical or educational activities in the field of neurotrauma. We hypothesized that a large portion of the award recipients will have remained in the field of neurotrauma and are actively involved in research, clinical and educational activities related to neurotrauma.

\section{METHODS}

\section{Selection of survey group}

A search in the ONF database was performed for studentships and fellowships awarded by ONF since its establishment in 1998. Only recipients whose award period terminated before July 2005 were included, to allow for at least one year of followup. The search strategy was supplemented by manually searching the grant files archives. Award recipients who had cancelled their award during the first year of its term were excluded from the survey. Recipients were contacted via direct email. Email addresses of non-responders were verified with their index supervisor and reminder emails were sent, seven and fourteen days after the initial contact.

\section{Survey Creation}

An explicit online survey was created, designed to collect the following data: baseline demographic data, degrees and awards received to date, current occupation and relevance to neurotrauma, number of publications during and following the
ONF award, involvement in professional activities and future career goals. In addition, participants were asked to comment on the contribution of the ONF award to their career and whether they are still collaborating with the researchers encountered during the award period. In order to minimize recall bias, data were retrieved from the award charts: award type (studentship/fellowship), studies pursued by the award recipient during the award period (Masters/PhD/Post-Doctoral), award amount and award period. Results of peer-review publications were verified by searching Medline database.

\section{Outcomes}

Our primary outcome was defined a-priori as the proportion of recipients currently active in the field of neurotrauma for more than $20 \%$ of their time, including research, clinical and educational activities. Secondary outcomes were the award impact on the recipients' career development, reflected by: number of awards achieved, number of neurotrauma related publications during and since the award period, current employment position, impact on current contacts and career goals. The aims of investigating the number of peer-reviewed publications of the recipients are twofold. The first is to establish whether the specific funded research was published and thus has had an impact on the neurotrauma knowledge base, and the second to use the publication number as a traditional method for measuring the impact of research capacity building. ${ }^{3}$ In order to minimize data heterogeneity, analyses were stratified according to the type of award granted (Masters/PhD/Post-Doctoral).

\section{Statistical Analysis}

Data are presented as proportions, means $( \pm$ standard deviation), or medians (interquartile range) as appropriate for the distribution normality. Categorical variables were compared using Chi square or Fischer exact tests, as appropriate. To test the association between number of publications and the award type, the non-parametric tests Kruskal Wallis and Spearman rank correlation coefficient were used. All comparisons were made using two sided significance level of $\mathrm{P}<0.05$. Statistical analysis was performed using SPSS for Windows V12.0.

\section{Results}

The search strategy revealed 42 past award recipients, of whom, $36(86 \%)$ completed the survey. The median time for the survey completion was 11 minutes (IQR 7.5-17.8). Basic characteristics of the six non-responders were similar to the responders in aspect of gender, age, type of award granted and award period. At the time of the survey, the mean follow-up period was $48 \pm 18$ months from the completion of the award (range 12-84 months). Of the 36 awards, 12 (33\%) were awarded to Post-Doctoral trainees and $24(67 \%)$ to graduate students (12 $\mathrm{PhD}$ and 12 Masters). The basic characteristics of the responders, stratified by the award type, are summarized in Table 1 . The major survey results are summarized in Table 2 .

\section{Relevance of current activity to neurotrauma}

Of the 36 award recipients, 25 (69\%) are currently involved in the field of neurotrauma (research, clinical or educational activities), of whom 20 (56\% of the total) practice the activity in 
Table 1: Basic characteristics of the included cohort, stratified by the award type

\begin{tabular}{c|l|l|l|l}
\hline & $\begin{array}{l}\text { Masters Award } \\
(\mathbf{n}=12)\end{array}$ & $\begin{array}{l}\text { PhD Award } \\
(\mathbf{n = 1 2})\end{array}$ & $\begin{array}{l}\text { Post-Doctoral } \\
\text { award (n=12) }\end{array}$ & Total (n=36) \\
\hline $\begin{array}{l}\text { Sex (females) } \\
\text { Total award amount }\end{array}$ & $9(75 \%)$ & $4(33 \%)$ & $7(58 \%)$ & $20(56 \%)$ \\
$\quad$ Mean \$ (CAD) \pm SD & $37,500 \pm 17,123$ & $50,667 \pm 16,999$ & $76,329 \pm 26,278$ & $54,832 \pm 25,833$ \\
$\quad \begin{array}{l}\text { Range \$ } \\
\text { Award length }\end{array}$ & $20,000-60,000$ & $20,000-80,000$ & $27,000-105,000$ & $20,000-105,000$ \\
$\quad$ Mean months \pm SD & $23 \pm 10$ & $31 \pm 10$ & $26 \pm 9$ & $27 \pm 10$ \\
$\quad \begin{array}{l}\text { Range } \\
\text { Follow-up period }\end{array}$ & $12-36$ & $12-48$ & $12-36$ & $12-48$ \\
$\quad \begin{array}{l}\text { Mean months } \pm \text { SD } \\
\text { Range }\end{array}$ & $42 \pm 21$ & $54 \pm 16$ & $49 \pm 18$ & $48 \pm 18$ \\
\hline
\end{tabular}

${ }^{1}$ from the end of award term and the survey date

more than $20 \%$ of their time. There were no significant differences between the degree type groups and their involvement in neurotrauma (Table 2).

A higher proportion of the $\mathrm{PhD}(7 / 12,58 \%)$ and PostDoctoral recipients $(7 / 12,58 \%)$ are involved in neurotraumarelated research more than $20 \%$ of their time, compared to the Masters group (4/12,33\%), but due to the small sample size this did not reach statistical significance (Fisher's exact, $\mathrm{p}=0.28$ ). Figure 2 demonstrates the different types of research practiced by the award recipients. None of the Masters students are currently involved in basic science research alone nor are any of the Post-Doctoral award recipients involved in clinical research alone.

Table 2: Results

\begin{tabular}{|c|c|c|c|c|}
\hline & $\begin{array}{l}\text { Masters graduate } \\
\text { award (n=12) }\end{array}$ & $\begin{array}{l}\text { PhD graduate } \\
\text { award }(n=12)\end{array}$ & $\begin{array}{l}\text { Post-Doctoral } \\
\text { award }(\mathrm{n}=12)\end{array}$ & Total $(\mathrm{n}=36)$ \\
\hline \multicolumn{5}{|l|}{ Current activity } \\
\hline Mostly clinical $^{1}$ & $4(33 \%)$ & $2(17 \%)$ & $4(33 \%)$ & $10(28 \%)$ \\
\hline Mostly research ${ }^{1}$ & $7(58 \%)$ & $8(67 \%)$ & $8(67 \%)$ & $23(64 \%)$ \\
\hline Mostly teaching ${ }^{1}$ & $1(8 \%)$ & $1(8 \%)$ & $0(0 \%)$ & $2(6 \%)$ \\
\hline Others & $0(0 \%)$ & $1(8 \%)$ & $0(0 \%)$ & $1(3 \%)$ \\
\hline Current involvement in research ${ }^{2}$ & $7(58 \%)$ & $9(75 \%)$ & $10(83 \%)$ & $26(72 \%)$ \\
\hline NT research & $4(33 \%)$ & $7(58 \%)$ & $7(58 \%)$ & $18(50 \%)$ \\
\hline NT research, clinical or teaching & $6(50 \%)$ & $8(67 \%)$ & $8(67 \%)$ & $22(61 \%)$ \\
\hline Involvement in professional activities ${ }^{3}$ & $7(58 \%)$ & $7(58 \%)$ & $9(75 \%)$ & $23(64 \%)$ \\
\hline $\begin{array}{l}\text { Current employment location } \\
\text { Ontario }\end{array}$ & $9(75 \%)$ & $10(83 \%)$ & $6(50 \%)$ & $25(69 \%)$ \\
\hline Canada, outside Ontario & $2(17 \%)$ & $0(0 \%)$ & $3(25 \%)$ & $5(14 \%)$ \\
\hline International & $1(8 \%)$ & $2(17 \%)$ & $3(25 \%)$ & $6(17 \%)$ \\
\hline Median number of publications ${ }^{4}$ & $1(0-2.5)$ & $4(2-7)$ & $7(4-10.5)$ & $4(1-7)$ \\
\hline Mean (range) & $1.8(0-7)$ & $4.8(0-12)$ & $7.3(3-12)$ & $4(0-12)$ \\
\hline \multicolumn{5}{|l|}{ Number of awards received ${ }^{5}$} \\
\hline $0-1$ & $5(42 \%)$ & $5(42 \%)$ & $6(50 \%)$ & $16(45 \%)$ \\
\hline $2-3$ & $5(42 \%)$ & $5(42 \%)$ & $3(25 \%)$ & $12(36 \%)$ \\
\hline$>3$ & $2(17 \%)$ & $2(17 \%)$ & $3(25 \%)$ & $7(19 \%)$ \\
\hline I received a CIHR award & $4(33 \%)$ & $6(50 \%)$ & $5(42 \%)$ & $14(39 \%)$ \\
\hline Average or less & $2(17 \%)$ & $1(8 \%)$ & $2(17 \%)$ & $5(14 \%)$ \\
\hline Much or very much & $10(83 \%)$ & $11(92 \%)$ & $10(83 \%)$ & $31(86 \%)$ \\
\hline \multicolumn{5}{|l|}{ My ONF contacts assisted me in } \\
\hline obtaining my current position & $6(50 \%)$ & $4(33 \%)$ & $8(67 \%)$ & $18(50 \%)$ \\
\hline Future goals related to NT & $7(58 \%)$ & $9(75 \%)$ & $7(58 \%)$ & $23(64 \%)$ \\
\hline
\end{tabular}

${ }^{1}$ more than $50 \%$ of the time; ${ }^{2}$ At least $20 \%$ of the recipient's time; ${ }^{3} \mathrm{e} . \mathrm{g}$. students supervision, peer-review, adjudication; ${ }^{4}$ From onset of award period and during follow-up period; ${ }^{5}$ e.g. scholarships, operating grants, prizes from the end of award term and the survey date; NT-neurotrauma

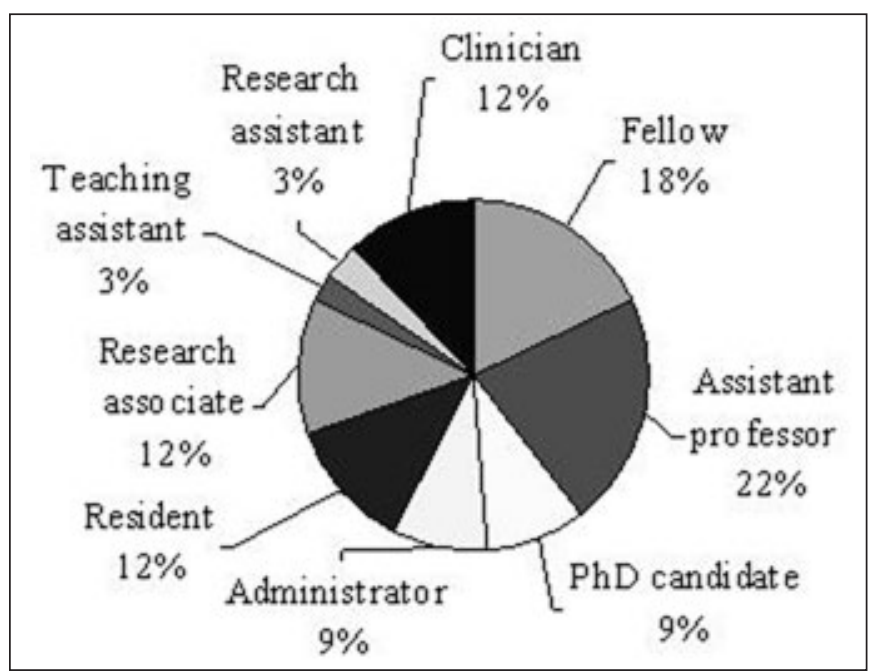

Figure 1: Distribution of grant recipients' current employment

Of the 14 recipients practicing clinical work, $10(71 \%)$ are related to neurotrauma, of whom seven (19\% of the full cohort) are involved in clinical activity more than $50 \%$ of their time. Of the 18 recipients involved in teaching, 15 (83\%) teach neurotrauma related subjects.

\section{Current Employment}

Of the combined group of award recipients, 34 (90\%) are currently employed at various levels of seniority (Figure 1). In order to identify career patterns, we categorized the employment data into fields of activity, namely research, clinical work and teaching, related or unrelated to neurotrauma. Twenty four of the $34(71 \%)$ employed recipients, work in research institutions; 6 $(18 \%)$ in clinical institutions and $1(1 \%)$ in industry. A total of 25 $(69 \%)$ of the award recipients are currently employed in Ontario (Table 2).

\section{Awarded Degrees}

The survey revealed that all of the 12 Masters students successfully completed their Masters degree. Four (33\%) attained or were in the process of a $\mathrm{PhD}$ degree and a further 2 (17\%) attained an MD degree. Of the $12 \mathrm{PhD}$ students, $10(83 \%)$ successfully completed their degree and $2(17 \%)$ are still in the process of thesis writing. Of the Post-Doctoral students, 3 (25\%) received an MD degree following their Post-Doctoral award and 4 who were holders of an MD degree $(33 \%)$ received a $\mathrm{PhD}$ degree after the completion of the award period. Thus, currently 7 (58\%) of the Post-Doctoral group hold both MD and PhD degrees.

\section{Research (Table 2)}

A total of 31 recipients $(86 \%)$ are currently involved in any kind of research, of whom $26(72 \%)$ are involved in research in at least $20 \%$ of their time. Masters award recipients, are involved slightly less in research $(7 / 12,58 \%)$ compared with the $\mathrm{PhD}$ 


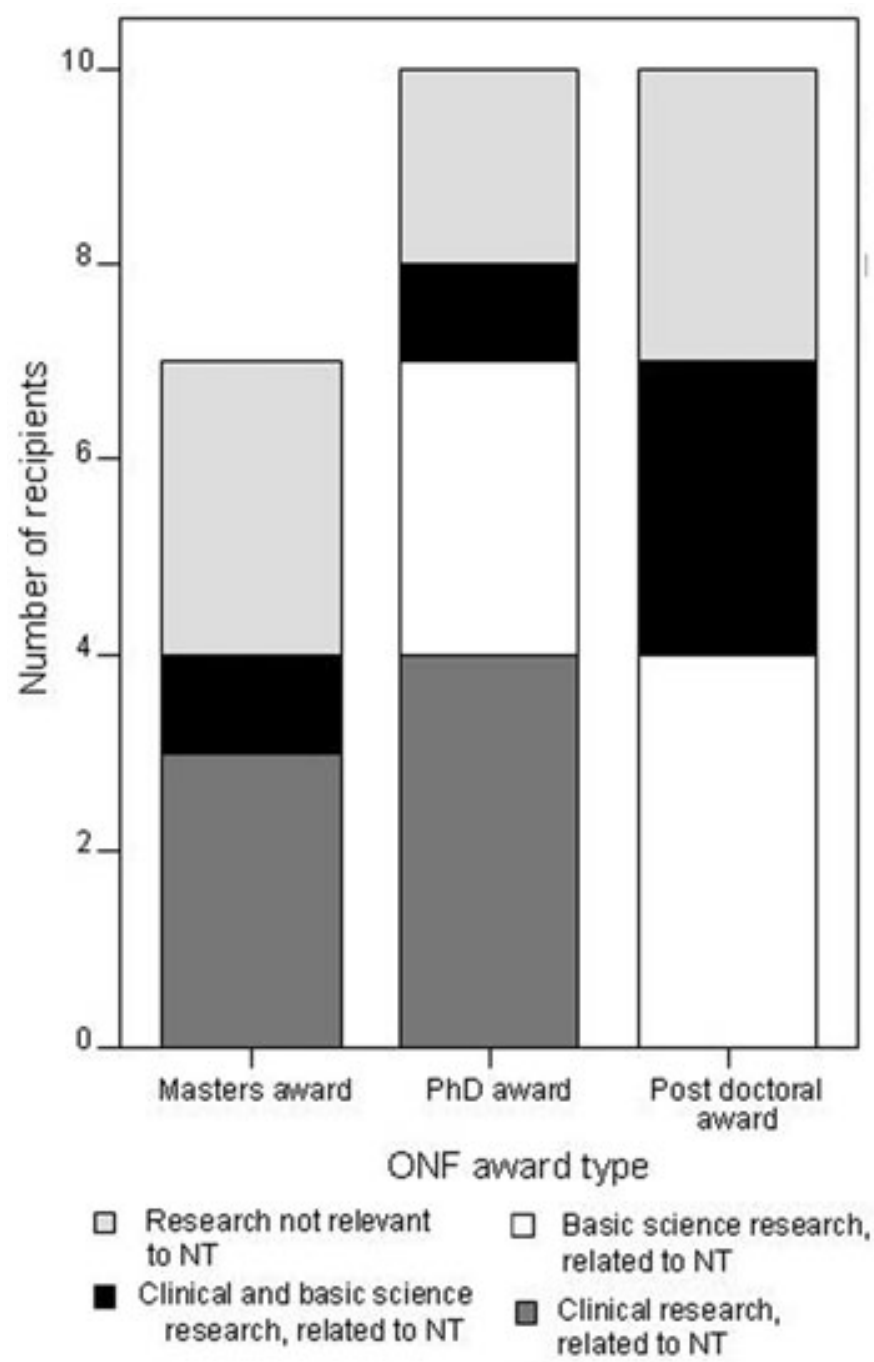

Figure 2: Types of research practiced by the award recipients

(9/12, 75\%) and Post-Doctoral award recipients (10/12, 83\%). Of the recipients currently in research, $11(36 \%)$ are involved in clinical research, $11(36 \%)$ in basic science and $9(29 \%)$ in both. None of these differences reached statistical significance. During the fellowship of the 36 grant recipients, 26 (72\%) conducted basic science research, of whom $12(46 \%)$ are currently still studying basic science, $8(30 \%)$ in both basic and clinical research, $3(12 \%)$ only clinical research and $3(12 \%)$ are currently not involved at all in research. Of the 10 (28\%) clinical research recipients, 7 (70\%) are still conducting clinical studies, $1(10 \%)$ in basic science and $2(20 \%)$ are not involved in research.

\section{Clinical work and teaching}

Many of the award recipients are currently involved in clinical and teaching activities, in addition to research. Fourteen
(39\%) are involved in clinical work, related and unrelated to neurotrauma but only $10(71 \%)$ and $2(14 \%)$ of the 14 recipients have clinical duties for more than $50 \%$ and $95 \%$ of their time, respectively. Eighteen recipients (50\%) are involved in teaching activities, but only a small proportion $(n=2,6 \%)$ are involved in teaching activities more than $50 \%$ of their time. These results were similar across the degree type groups (Table 2).

\section{Impact of ONF award and contacts on career}

The majority of the recipients $(31 / 36,86 \%)$ believe that their ONF award impacted on their career 'much' or 'very much'. Eighteen of the award recipients (50\%) stated that the contacts developed during their award period assisted them in obtaining their current position, with the Post-Doctoral recipients benefiting most (Table 2). Twenty (53\%) award recipients are still actively collaborating with the researchers who were involved in the ONF award. The results did not differ significantly between the three award type groups.

\section{Professional Activities}

Recipients were asked about their involvement in extracurriculum professional activities, such as journal peer review and supervision of graduate students. A total of $23(64 \%)$ of the recipients are involved in various professional activities, with a slightly higher involvement rate amongst the Post-Doctoral recipient group (Table 2). Fifteen (42\%) are involved in journal review of which 11 (31\% of the total cohort) are reviewing neurotrauma related journals. Twelve $(33 \%)$ of the award recipients are currently supervising graduate students, of whom nine $(75 \%)$ are studying in the field of neurotrauma.

\section{Publications}

A total of 167 articles were published in various scientific journals, with a median of 4 (1-7) publications per recipient over the follow-up period. The counting started from the second year of the award period, since we assumed that prior publications were not a product of the ONF award. As expected from the level of training, the mean number of publications correlated with the degree level, with the Post-Doctoral group publishing the most and the Masters group having the least (Spearman correlation coefficient, $\mathrm{r}=0.6, \mathrm{p}<0.001$; Kruskal Wallis=12.8, $\mathrm{p}=0.02$ ).

\section{Future Career Goals}

The recipients were asked about future career goals for the next five years. A total of $23(64 \%)$ of the recipients expressed neurotrauma related career goals (Table 2). All 21 recipients who are currently involved in neurotrauma related activities (more than $20 \%$ of their time) also see their career goals in the field of neurotrauma, compared with only 2 of the others $(\mathrm{p}<0.001$, Fisher's exact test).

\section{Profile of recipients who left Ontario}

Of the 11 award recipients (31\%) who left Ontario, 5 are working in other Canadian provinces, 5 in the USA and one in Japan. As we do not record the nationality of our recipients, it is not known what proportion of the six were international trainees at the time of the award. The Post-Doctoral group formed the 
highest proportion of "leavers" $(6 / 11,55 \%)$, followed by Masters Students $(3 / 11,27 \%)$ and $\mathrm{PhD}$ Students $(2 / 11,18 \%)$.

\section{Discussion}

To the best of our knowledge, this is the first capacity building outcome study performed in neurotrauma, and one of very few that have ever been performed among Canadian funding agencies. There is no consensus on the optimal method to measure effectiveness of research capacity building. ${ }^{3} \mathrm{We}$, therefore, included a wide variety of outcomes to ensure a comprehensive assessment of the recipient's profile. A high proportion $(86 \%)$ of past trainees awarded fellowships and studentships in the field of neurotrauma are currently involved in research at any amount of their time, of which over two thirds are involved in neurotrauma research. Sixty one percent of the recipients are involved in the field of neurotrauma for at least $20 \%$ of their time, including research, clinical or teaching activities. Since the primary aim of funding trainee programs is to build neurotrauma capacity, we believe that these results reflect successful outcome.

Our results on the overall research activity favorably compare with programs in the fields of Geriatric, Primary Care and General Medicine, where only $11-48 \%$ of the recipients were significantly involved in research. ${ }^{5-7}$ A quarter of the recipients are supervising neurotrauma-related graduate students, which is a direct contribution to creating capacity in the next generation of students. Similar to other capacity building funding agencies, ${ }^{6,8-10}$ a high majority of our recipients (86\%) feel that the ONF award had a substantial impact on their career. This positive feedback, coupled with the fact that the majority identified their career goals as neurotrauma-related, is promising to the local field of neurotrauma.

Although the primary aim of the fellowships is to build research capacity, the trainees contribute directly to the field also by conducting research projects during the award period supervised by leading researchers. Indeed, the high publication rate during and after the award periods supports this notion. Only $14 \%$ had no publications to date, all of whom were Masters students. The peer-review publication rate among the PostDoctoral recipients (1.5 peer-review publications per personyear) is comparable to Post-Doctoral medical fellowships in other fields; 1.4 articles per person-year in primary care, ${ }^{5} 2.8$ articles per person-year in Arthritis ${ }^{9}$ and less than one in Gastroenterology. ${ }^{8}$ In addition to publication success, the recipients have succeeded in obtaining a wide range of awards, scholarships, and operating grants with a mean award number of 2.3 per recipient. Moreover, the success of $42 \%$ of recipients in obtaining a CIHR funding is impressive.

No significant differences were found in the outcomes between the Masters, $\mathrm{PhD}$ and Post-Doctoral groups. The cost of a Masters award is half of the Post-Doctoral award, and since outcomes are similar, the former may prove more cost-effective at the funding agency level. Nonetheless, the investment in the Post-Doctoral students may reap additional direct benefits from a fruitful funded research period, as reflected by significantly more publications produced by the senior trainees in comparison to the Masters students. Although no formal cost-effectiveness analysis was performed, the balance of funding all trainee levels seems satisfactory.
A literature search revealed only two similar surveys from Canada, the first performed by the Canadian Association of Gastroenterology (CAG) and the other by the Arthritis Society of Canada (TAS). We supplemented the search by contacting major funding agencies in Canada, but no further publications were identified (National Cancer Institute of Canada, Alberta Heritage Foundation for Medical Research, Canadian Institutes of Health Research, Heart and Stroke Foundation of Canada, Michael Smith Foundation for Health Research, and The Multiple Sclerosis Society of Canada). The CAG survey performed on 87 clinicians and $\mathrm{PhD}$ fellows awarded during 1992-2002 found that $36 \%$ of its fellows currently hold faculty positions, of which two thirds are in Canadian institutions. ${ }^{8}$ This is slightly more than the $22 \%$ found here. However, all of the ONF recipients who hold faculty positions are employed in Canadian institutions compared with only two thirds in the CAG survey. Ontario appears to be successful in terms of offering suitable neurotrauma employment opportunities to its graduates, with relatively low brain drain for such a young and potentially mobile group. The survey performed by TAS in 1994 found that $73 \%$ of the 37 research fellowship recipients were successful in obtaining research grant support, ${ }^{9}$ comparable to our fellowship recipients. An impressive rate of $96 \%$ held academic rankings, but this was determined by a non-representative subset of 25 research fellowship recipients who agreed to submit their CV.

We conclude that a majority of the award recipients have neurotrauma-related interests, mostly in Canada. The results of this study encourage us to continue offering funding at trainees level, and could also be used by other funding agencies for strategic planning and comparisons. The relatively high number of trainees who remain in the neurotrauma field and succeed in their careers additionally reflects on the rigorous ONF review process. Additionally, the existence of the ONF may have an impact on the decision making of graduate students to enter the neurotrauma field, due to the availability of research funding. Our study does, however, suffer from several weaknesses. The small sample size does not permit systematic analytical comparisons and restricts our study to descriptive analysis. The follow-up period of four years from the conclusion of the award implies medium-term period. We intend to continue and monitor our past trainees further into the long-term period. Another potential limitation is that participants may be biased to provide favorable answers to satisfy potential funding source. However, by virtue of this possible bias, responders answering this way have probably strong future neurotrauma-related goals and, thus, the bias is in the same direction as the true outcome. Finally, it is difficult to assume cause and effect relationship between the awards given and the current high involvement in research and neurotrauma, as applicants to our Foundation are already interested in neurotrauma research. Despite this potential 'confounding by indication' bias and the other weaknesses, the multiple outcomes selected, the high participation rate, and the high positive response likely reflect real life and support the validity of our results. ONF, as a strategic foundation committed to maximum return on its investment, is currently in the process of reassessing its capacity building programs. This study provides evidence to determine the most effective approach for creating a cadre of people involved in research, clinical and 
educational activities related to neurotrauma that will eventually improve quality of life of ABI and SCI consumers.

\section{ACKNOWLEDGEMENTS}

All the past ONF past award recipients for their kind cooperation in completing the survey questions.

\section{REFERENCES}

1. Zitnay GA. Lessons from national and international TBI societies and funds like NBIRTT. Acta Neurochir Suppl. 2005;93:131-3.

2. Campbell SM, Roland MO, Bentley E, Dowell J, Hassall K, Pooley JE, et al. Research capacity in UK primary care. Br J Gen Pract. 1999 Dec;49(449):967-70.

3. Cooke J. A framework to evaluate research capacity building in health care. BMC Fam Pract. 2005 Oct 27;6:44.

4. Rosa S. [The Canadian Institute of Aging: knowledge, innovation and action]. Med Sci (Paris). 2006;22(3):323-6.

5. Steiner JF, Lanphear BP, Curtis P, Vu KO. The training and career paths of fellows in the National Research Service Award (NRSA) Program for Research in Primary Medical Care. Acad Med. 2002 Jul;77(7):712-8.
6. Simon SR, Shaneyfelt TM, Collins MM, Cook EF, Fletcher RH. Faculty training in general internal medicine: a survey of graduates from a research-intensive fellowship program. Acad Med. 1999 Nov;74(11):1253-5.

7. Medina-Walpole A, Barker WH, Katz PR, Karuza J, Williams TF, Hall WJ. The current state of geriatric medicine: a national survey of fellowship-trained geriatricians, 1990 to 1998. J Am Geriatr Soc. 2002 May;50(5):949-55.

8. McKay DM, Daniels S. Canadian Association of Gastroenterology - Canadian Institutes of Health Research - pharmaceutical partner postdoctoral operating fellowship programme: an outstanding success that continues to excel! Can J Gastroenterol. 2003 Jul;17(7):437-9.

9. McKendry RJ, Freeman C, Dale P. The effects of Arthritis Society fellowships on career choice. J Rheumatol. 1994 Nov;21 (11):2131-5 .

10. Bell R, Norman M, Lamb B, Holliday J, Leggett-Frazier N. Assessing the effectiveness of a clinical fellowship on diabetes in enhancing diabetes care in North Carolina. Diabetes Educ. 2000 Jan-Feb;26(1):41-2, 53-4, 7. 